LINGUA, Vol. 14, No. 2, September 2017

p ISSN: 1979 9411; e ISSN: 2442 238X

Http://lingua.pusatbahasa.or.id; Email: presslingua@gmail.com

Center of Language and Culture Studies, Surakarta, Indonesia

Suprayitno, Edy. 2017. Etika Pengembaraan Masyarakat Jawa pada Naskah Serat Dewa Ruci

Karya R. Ng. Yasadipura I dalam Perspektif Kehidupan Modern.

Lingua (2017), 14(2): 141 154.

\title{
ETIKA PENGEMBARAAN ILMU MASYARAKAT JAWA \\ PADA NASKAH SERAT DEWA RUCI KARYA R. Ng. YASADIPURA I DALAM PERSPEKTIF KEHIDUPAN MODERN
}

\author{
Edy Suprayitno \\ STKIP PGRI Ponorogo \\ edhysobatq@gmail.com
}

\begin{abstract}
This research examines the etiques in acquiring knowledge in the Javanese community tradition. The object of this study was Dewa Ruci script by R.Ng. Yasadipura I. The research used qualitative descriptive approach and content analysis as the research design assigning the sociology theory for literature. The finding showed an evidence when acquiring the knowledge, the Javanese always taught four aspects of heritages to their descendants that is inherently asserted in the perspective of the Javanese community and their philosophy. Those aspects attached within the spirit of the Javanese consisted of: (a) enthusiasm, (b) do not give up easily, (c) persistence, and (d) students' obedience.
\end{abstract}

Key words: learning etiquette, Javanese, Serat Dewa Ruci script

Dalam mencari ilmu keberadaan etika tidak dapat dipisahkan. Etika melekat dan menjadi sesuatu yang harus dilakukan oleh si pencari ilmu. Berbicara etika pada hakikatnya membicarakan kesusilaan atau norma. Kesusilaan dapat diartikan sebuah tingkah laku manusia yang merujuk pada kebaikan. Kebaikan di sini bukan sekedar kebaikan, tetapi lebih merujuk pada manusia sebagai persona. Sehingga etika ini yang menjadikan manusia dapat memandang sesuatu baik dan buruk. Sementara Suseno mengatakan bahwa etika merupakan filsafat mengenai bidang moral (1993:6). Dalam arti yang lebih luas yaitu keseluruhan norma dan penilaian yang dipergunakan oleh masyarakat yang bersangkutan untuk mengetahui bagaimana manusia seharusnya menjalankan kehidupannya.

Etika berguru ala manusia Jawa tersebut juga tercermin dalam berbagai karya sastra yang lahir dari pengarang berbudaya Jawa. Karena karya sastra merupakan abstraksi atau tiruan kehidupan nyata. Maka karya sastra yang dihasilkan oleh manusia yang berbudaya Jawa cenderung mencerminkan pola kehidupan masyarakat Jawa. Hal ini seperti yang diungkapkan oleh Abrams dalam Endraswara sastra juga merupakan cerminan dari kehidupan masyarakat seperti yang diungkapkan (2011:88). Pernyataan ini menegaskan bahwa keberadaan karya sastra walaupun hanya sebatas cerita rekaan, tapi diilhami oleh kehidupan realitas. Selain itu penulis teks sastra juga anggota masyarakat yang senantiasa bersinggungan dengan manusia lain. Sehingga menjadikan karya rekaannya memiliki kemiripan dengan realitas yang dilihat dan dirasakan. 
LINGUA, Vol. 14, No. 2, September 2017

p ISSN: 1979 9411; e ISSN: 2442 238X

Http://lingua.pusatbahasa.or.id; Email: presslingua@gmail.com

Center of Language and Culture Studies, Surakarta, Indonesia

Suprayitno, Edy. 2017. Etika Pengembaraan Masyarakat Jawa pada Naskah Serat Dewa Ruci

Karya R. Ng. Yasadipura I dalam Perspektif Kehidupan Modern.

Lingua (2017), 14(2): 141 154.

Berpijak dari uraian di atas, maka keberadaannya karya sastra dapat mempengaruhi dan dipengaruhi oleh masyarakat. Sebab karya sastra diciptakan oleh sastrawan untuk dinikmati dan dipahami serta dimanfaatkan oleh masyarakat (Damono, 1984: 16). Masyarakat dapat mengambil dan menjadikan pesan yang ada dalam karya sastra. Sebab dalam karya sastra banyak nilai dan pesan moral yang ingin disampaikan oleh pengarang. Nilai dan pesan tersebut kemudian dijadikan dijadikan acuan hidup oleh pengarang.

Salah satu karya sastra adalah naskah lakon pewayangan. Dalam hal ini masuk dalam kategori sastra tulis. Wayang sudah ada sejak zaman dulu, merupakan wujud kebudayaan. Dalam pementasan wayang pasti ada cerita atau lakon yang dimainkan. Cerita atau lakon wayang kulit tersebut menyimpan banyak nilai dan pesan moral yang tersirat di dalamnya. Wayang dimainkan oleh seorang Dalang dari kata Arab yaitu dalla artinya menunjukkan jalan yang benar (Endraswara, 2010:91). Jadi Dalang bertugas membina, menunjukkan jalan bagi manusia lain melalaui pesan-pesan moral yang disampaikan melalui kesenian wayang.

Kesenian wayang memunyai bermacam cerita dan lakon. Lakon wayang kulit pada dasarnya berasal dari dua induk (babon) besar, yaitu cerita Ramayana dan Mahabarata (Endraswara, 2010:92). Dari kedua cerita tersebut, kemudian diturunkan menjadi berbagai cerita lain. Salah satunya adalah cerita Serat Dewa Ruci yang dikarang oleh R. Ng. Yasadipura I. Cerita Serat Dewa Ruci yang dikarang oleh R. Ng. Yasadipura I berinduk pada cerita Mahabarata.

Cerita Serat Dewa Ruci mengisahkan tentang pencarian ilmu yang dilakukan oleh Bima atau Raden Werkudara dengan cara berguru pada Pendhita Druna. Dalam perjalanannya Pendhita Druna memunyai niat buruk untuk mencelakai Bima. Hal ini Pendhita Druna merupakan bagian dari Kurawa. Perseteruan Pandawa dan Kurawa akhirnya menyeret Pendhita Druna mencari tipu muslihat untuk membunuh Bima. Sehingga diharapkan dalam Perang Baratayudha Pandawa dapat dikalahkan dengan mudah oleh Kurawa.

Menelaah etika berguru dalam naskah Serat Dewa Ruci tersebut membutuhkan teori yang sesuai. Dalam penelitian ini menggunakan teori sosiologi sastra. Keberadaan teori sosiologi sastra berkenaan dengan sikap dan etika yang dilakukan dalam menuntut ilmu. Walaupun yang menjadi objek penelitian ini merupakan sebuah cerita dalam pewayangan bukan manusia sesungguhnya. Tapi, keberadaan cerita dalam karya sastra merupakan duplikat dari kehidupan nyata. Seperti yang diungkapkan Abram bahwa sastra juga merupakan cerminan dari kehidupan masyarakat (dalam Endraswara, 2011: 88). Sehingga ini dapat dimaknai bahwa alur cerita dalam karya sastra pada hakikatnya merupakan cerminan dalam kehidupan realitas.

Di sisi lain, ada dua kecenderungan yang paling utama dalam menelaah sosiologi sastra diantaranya, (1) pendekatan yang berdasarkan pada anggapan bahwa sastra merupakan cermin proses sosial ekonomi belaka, (2) pendekatan yang mengutamakan teks sastra sebagai bahan penelaahan yang kemudian dicari aspek-aspek sosial dari karya sastra (Damono. 1984: 34). Berpijak pengertian di atas, sosiologi dan sastra memiliki kecenderungan yang sama, yaitu menjadikan manusia dan 
LINGUA, Vol. 14, No. 2, September 2017

p ISSN: 1979 9411; e ISSN: 2442 238X

Http://lingua.pusatbahasa.or.id; Email: presslingua@gmail.com

Center of Language and Culture Studies, Surakarta, Indonesia

Suprayitno, Edy. 2017. Etika Pengembaraan Masyarakat Jawa pada Naskah Serat Dewa Ruci

Karya R. Ng. Yasadipura I dalam Perspektif Kehidupan Modern.

Lingua (2017), 14(2): 141 154.

lingkungannya sebagai objeknya. Sosiologi menjadikan manusia sebagai objek kajiannya, sedangkan sastra menjadikan manusia dan kehidupanya sebagai objek, sekaligus pengarang sastra juga merupakan manusia sebagai anggota masyarakat. Oleh sebab itu sosiologi sastra merupakan salah satu pisau bedah dalam mengkaji karya sastra.

\section{METODE}

Dalam penelitian ini metode yang digunakan adalah kualitatif deskriptif. Metode kualitatif deskriptif dipilih dengan mendasarkan pada kesesuaian objek penelitiannya. Objek penelitiannya berupa dokumen atau teks sastra berjudul Naskah Serat Dewa Ruci karangan R.Ng. Yasadipura I. Metode penelitian kualitatif merupakan prosedur penelitian yang menghasilkan data deskriptif berupa kata-kata tertulis atau lisan yang sifat-sifat suatu individu, keadaan atau gejala dari kelompok yang dapat diamati (Moleong 2007:6).

Pengumpulan data pada sebuah kegiatan penelitian harus dilakukan secara sistemik. Hal ini difungsikan supaya data penelitian yang didapatkan sesuai dan lengkap. Teknik pengumpulan data dalam penelitian ini adalah (1) teknik baca, (2) simak dan (3) catat. Pengertian teknik baca, pada hakikatnya mengarah pada kegiatan membaca teks yang menjadi objek penelitian secara komprehensif. Kemudian penyimakan secara cermat, terarah, dan teliti terhadap sumber data. Setelah itu melakukan pencatatan terhadap kutipan dalam teks yang sesuai dengan indikator dalam penelitian.

Teknik analisis data dalam penelitian ini adalah analisis isi (content analysis) dengan cara membaca, memahami, dan mencermati secara intens Serat Dewa Ruci karangan R. Ng. Yasadipura I sebagai sumber datanya. Oleh karena itu, analisis ini akan membongkar cerita Serat Dewa Ruci karangan R. Ng. Yasadipura I untuk menemukan etika berguru yang terkandung di dalamnya. Langkah-langkah analisis isi ini mencakup tahapan (1) mengumpulkan data, (2) mereduksi data, (3) pemaparan data, (4) pengkodean data, (5) menginterpretasi data, dan (6) menarik kesimpulan yang mengarah pada makna yang berkaitan dengan fokus penelitian. Pada akhirnya, penafsiran yang telah disimpulkan itu dideskripsikan sebagai hasil penelitian.

\section{HASIL DAN BAHASAN}

Pembahasan dalam penelitian ini menemukan empat etika yang harus dilakukan dalam menuntut ilmu dalam naskah Serat Dewa Ruci karangan R.Ng. Yasadipura I. Empat temuan tersebut antara lain (a) semangat, (b) pantang menyerah, (c) tidak mudah goyah, dan (d) patuh pada perintah guru.

\section{Semangat}

Pengembaraan (pencarian) ilmu membutuhkan sebuah pengorbanan. Tidak hanya pengorbanan dalam bentuk material tetapi juga non material. Selain itu juga harus mengorbankan tenaga, pikiran, dan waktu. Naskah Serat Dewa Ruci karangan R.Ng. Yasadipura I mengajarkan etika menuntut ilmu dalam prespektif budaya Jawa. Melalui 
LINGUA, Vol. 14, No. 2, September 2017

p ISSN: 1979 9411; e ISSN: 2442 238X

Http://lingua.pusatbahasa.or.id; Email: presslingua@gmail.com

Center of Language and Culture Studies, Surakarta, Indonesia

Suprayitno, Edy. 2017. Etika Pengembaraan Masyarakat Jawa pada Naskah Serat Dewa Ruci

Karya R. Ng. Yasadipura I dalam Perspektif Kehidupan Modern.

Lingua (2017), 14(2): 141 154.

tokoh utamanya yang bernama Raden Wrekudara. Pelukisan alur cerita tersebut begitu kuat. Raden Werkudara dengan penuh semangat berguru kepada Pendhita Druna. Di balik keberadaannya sebagai seorang bangsawan, tapi tidak menyurutkan niatnya untuk menuntut ilmu.

Pencarian ilmu yang dilakukan Raden Wrekudara membawanya pada tugas dari sang guru yang tidak sulit dituntaskan. Yaitu mencari air suci Perwitasari di Gunung Candramuka dan dasar lautan sebagai syarat menerima ilmu sangkan paraning dumadi. Tapi, kemantaban hati dan semangat telah membara dalam diri Raden Wrekudara seperti tampak pada kutipan (1) dan (2).

(1) Arya Sena lajeng lampahneki, rapteng wana langkug sukaning tyas, tirta ning pangupayane, saking tuduhing guru, tan anyipta upaya sandi, bebaya den geng ambah, tyasira mung ketung, kacaryan, dennya ngupaya, kang tirta neng aning Candramuka wukir, amarga sengkeng den ambah. Jurang pereng runggut, kang wanadri, sato wana bubar kang katrajang, andanu sangsam lan banteng, among wanara lutung, neng pang wreksa sangsaya mancit...

\section{Terjemahan}

Arya Sena terus berjalan, sampai di hutan hatinya sangat gembira, air jernih yang dicari, dari petunjuk gurunya, tak mengira bahwa itu suatu muslihat, bahaya besar ditempuhnya, hatinya hanya memperhitungkan, dengan gembira ia mencari, si air jernih di gunung, Candramuka, jalan sulit ditempuhnya. Jurang curam dan lebatnya hutan, satwa bercerai-berai diterjangnya, kerbau, kijang, dan banteng hanya kera di pucuk pohon, yang semakin memanjat tinggi.....

(2) Lajeng ndhedher Arya Sena, wus tebih manjung wanadri, tan kestri durgameng hawan, tan ana bebaya kesthi, sagong wong tepis iring, pra samya gawok angrungu, lampahe Arya Bima, lir naga krura ngajrihianrang baya amrih tuduhing ngagesang

\section{Terjemahan}

Semakin jauh perjalanan Arya Sena, sudah masuk ke dalam hutan, tak terpikirkan bahaya di perjalanan, tak ada bahaya dilihatnya, orang-orang yang tinggal diperbatasan, semua heran mendengarnya, perjalanan Arya Sena bagaikan naga yang sangat menakutkan, menyerang bahaya agar tercapai tujuan hidupnya.

Pengembaraan ilmu memang harus dilakukan dengan penuh semangat,sehingga diharapkan semangat yang menyala tersebut dapat berbuah manis. Semangat itu dicontohkan Raden Wrekudara dalam kutipan di atas. Dengan penuh semangat Raden Wrekudara berjalan menyusuri hutan belantara tanpa menghiraukan 
LINGUA, Vol. 14, No. 2, September 2017

p ISSN: 1979 9411; e ISSN: 2442 238X

Http://lingua.pusatbahasa.or.id; Email: presslingua@gmail.com

Center of Language and Culture Studies, Surakarta, Indonesia

Suprayitno, Edy. 2017. Etika Pengembaraan Masyarakat Jawa pada Naskah Serat Dewa Ruci

Karya R. Ng. Yasadipura I dalam Perspektif Kehidupan Modern.

Lingua (2017), 14(2): 141 154.

bahaya yang mengancam. Secara logika hutan belantara memberikan bahaya pada seseorang yang menyusurinya. Terlebih perjalanan itu dilakukan seorang diri. Dalam konteks ini, keberadaan hutan belantara yang membahayakan tidak menyurutkan semangat Raden Wrekudara. Dalam pikirannya hanya satu yakni menuntaskan tugas dari gurunya untuk mendapatkan sang air suci tersebut.

Sikap yang ditunjukkan oleh Wrekudara tersebut sejalan dengan falsafah Jawa "Ngelmu iku Kalakone Kanthi Laku" yang bermakna mencari ilmu tercapainya lewat proses atau perjalanan lahir batin (Santosa, 2012:73). Falsafah tersebut apabila dimaknai lebih dalam maka yang menjadi titik fokus pencarian ilmu bukan hanya hasil akhir, tapi juga proses menuju hasil. Sehingga pemaknaan mendapatkan ilmu tersebut akan lebih dalam apabila memahami dan menghayati perjalanannya.

Apabila dihubungkan dengan falsafah tersebut maka yang dilakukan Raden Wrekudara adalah implementasi dari falsafah Jawa. Raden Wrekudara melakukan proses pencarian ilmu dengan perjalanan lahir batin. Tidak mendasarkan pada keterpaksaan terhadap perintah sang guru, tapi murni dan ikhlas lahir batin. Perjalanan yang diiringi keikhlasan lahir dan batin tersebut pada akhirnya membawa Raden Werkudara bertemu dengan Dewa Ruci.

Dalam konteks kehidupan nyata semangat pengembaraan ilmu yang dilakukan oleh Raden Wrekudara tersebut harus dijadikan teladan. Pencarian ilmu tidak mungkin akan berhasil apabila tidak ada semangat yang menyertainya. Sehingga, semangat mencari ilmu harus tertanam dalam benak para peserta didik. Semangat tersebut dapat diimplementasikan dalam bentuk berangkat ke sekolah tepat waktu, mengerjakan tugas dari guru tepat waktu, mengikuti aturan-aturan yang berlaku di dekolah, dan sebagainya. Periksa kutipan (3).

Samana prapto sampun Candramuka guwaning wukir, sela-sela binubak, binuwangan gupuh, sanget denira ngupaya, tirta maya ingubres datan kapanggih, Arya sena sangsaya. Apan sanget denira ngulati, Tirta Maya kang guwa binubrah padhang tan ana tandhane, Tirta Maya nggenipun, jroning guwa den osak-asik, saya lajeng mangengah, Sena lampahipun, denira ngulati toya...

\section{Terjemahan}

Setelah sampai di gua Gunung Candramuka, bebatuan disingkirkan, dengan sungguh-sungguh ia mencari, air maya dicari tidak ada, Arya Sena semakin bersungguh-sungguh dalam mencari, air maya dalam gua yang sudah dirusak sehingga tampak terang benderang tanpa tanda-tanda, tempat air maya, dalam gua itu diobrak-abrik, semakin menuju ke tengah, Sena berjalan, dalam usaha mencari air, sang air jernih....

Bukti lain, semangat yang dimiliki oleh Raden Wrekudara dalam menuntu ilmu tercermin dalam kutipan di atas. Dalam cerita tersebut dikisahkan semangat Raden 
LINGUA, Vol. 14, No. 2, September 2017

p ISSN: 1979 9411; e ISSN: 2442 238X

Http://lingua.pusatbahasa.or.id; Email: presslingua@gmail.com

Center of Language and Culture Studies, Surakarta, Indonesia

Suprayitno, Edy. 2017. Etika Pengembaraan Masyarakat Jawa pada Naskah Serat Dewa Ruci

Karya R. Ng. Yasadipura I dalam Perspektif Kehidupan Modern.

Lingua (2017), 14(2): 141 154.

Wrekudara dalam mencari air suci di Gua Tribasara Gunung Candramuka. Bentuk gua yang besar dan bebatuan menyulitkan Raden Wrekudara mendapatkan air yang dimaksud. Akhirnya jalan yang ditempuh dengan cara menghancurkan bebatuan. Sikap yang ditunjukkan oleh Raden Wrekudara tersbut menggambarkan semangat yang membara. Walaupun, secara logika tidak mungkin ada air di balik bebatuan, tapi dengan penuh keyakinan Raden Wrekudara tetap gigih berusaha mendapatkannya.

Semangat dalam mencari ilmu yang ditunjukkan oleh Raden Wrekudara cenderung bertolak belakang dengan realitas kehidupan modern. Di saat kebutuhan hidup tercukupi, justru semangat menuntut ilmu yang dimiliki para peserta didik terkadang rendah. Salah satu contoh banyak peserta didik yang enggan mengerjakan tugas dari guru, sering terlambat sekolah, kurang mematuhi aturan sekolah, malas, suka membolos, dan sebagainya. Perilaku tersebut mengindikasikan sikap negatif dalam mencari ilmu. Sehingga tugas guru sebagai ujung tombak pendidikan harus membenahi mental dan perilaku peserta didik tersebut.

\section{Pantang Menyerah}

Pengembaraan ilmu harus didukung oleh karakter yang kuat, pantang menyerah salah satu contohnya. Perjalanan menuntut ilmu pasti akan melalui berbagai halangan. Maka diperlukan karakter pantang menyerah. Tapi realitasnya banyak orang yang menyerah menuntut ilmu. Berbagai masalah yang datang dalam perjalanan menuntut ilmu, menjadikan banyak orang berguguran. Satu contoh, ada peserta didik yang memutuskan berhenti sekolah karena tidak kuat menanggung beban tugas sekolah. Selain itu, ada pula peserta didik yang memutuskan berhenti sekolah karena lebih memilih menggunakan waktu untuk aktifitas yang lain..

Fenomena tersebut bisa diibaratkan menyerah dalam menghadapi rintangan menuntut ilmu. Padahal dalam ajaran budaya Jawa menuntut ilmu merupakan keharusan. Karena dalam budaya Jawa tidak menginginkan manusia Jawa menjadi seseorang yang bodoh. Sehingga, manusia Jawa pada zaman dahulu ketika beranjak remaja pergi dari rumah mengembara mencari guru. Mereka pantang untuk pulang sebelum mendapatkan ilmu yang dimaksud. Sehingga, manusia Jawa dahulu mempunyai karakter pantang menyerah sebelum mendapatkan sesuatu yang diinginkan.

Dalam naskah Serat Dewa Ruci karangan R.Ng. Yasadipura I, banyak ditemukan nilai-nilai pantang menyerah dalam pengembaraan ilmu. Nilai-nilai tersebut diantaranya tersirat melalui perwatakan tokoh utamanya dan tersurat melalui alur cerita yang dilukiskan oleh pengarang. Nilai itu tercermin dalam kutipan (4) dan (5).

(4) Arya Sena lajeng lampahneki, rapteng wana langkug sukaning tyas, tirta ning pangupayane, saking tuduhing guru, tan anyipta upaya sandi, bebaya den geng ambah, tyasira mung ketung, kacaryan, dennya ngupaya, kang tirta neng aning Candramuka wukir, amarga sengkeng den ambah. Jurang pereng runggut, kang wanadri, sato wana bubar kang katrajang, andanu sangsam lan banteng, among wanara lutung, neng pang wreksa sangsaya mancit... 


\section{Terjemahan}

Arya Sena terus berjalan, sampai di hutan hatinya sangat gembira, air jernih yang dicari, dari petunjuk gurunya, tak mengira bahwa itu suatu muslihat, bahaya besar ditempuhnya, hatinya hanya memperhitungkan, dengan gembira ia mencari, si air jernih di gunung, Candramuka, jalan sulit ditempuhnya. Jurang curam dan lebatnya hutan, satwa bercerai-berai diterjangnya, kerbau, kijang, dan banteng hanya kera di pucuk pohon, yang semakin memanjat tinggi.....

(5) Lajeng ndhedher Arya Sena, wus tebih manjung wanadri, tan kestri durgameng hawan, tan ana bebaya kesthi, sagong wong tepis iring, pra samya gawok angrungu, lampahe Arya Bima, lir naga krura ngajrihianrang baya amrih tuduhing ngagesang

\section{Terjemahan}

Semakin jauh perjalanan Arya Sena, sudah masuk ke dalam hutan, tak terpikirkan bahaya di perjalanan, tak ada bahaya dilihatnya, orang-orang yang tinggal diperbatasan, semua heran mendengarnya, perjalanan Arya Sena bagaikan naga yang sangat menakutkan, menyerang bahaya agar tercapai tujuan hidupnya.

Raden Wrekudara atau Arya Sena harus melalui hutan belantara, gunung, dan jurang untuk mendapatkan air suci yang menurut gurunya berada di Gua Tribasara Gunug Candramuka. Hutan belantara, gunung, jurang, merupakan hambatan dalam perjalanan mencari ilmu. Untuk menaklukkan hambatan tersebut dibutuhkan nyali dan semangat pantang menyerah. Raden Wrekudara dalam hatinya tidak terbersit keinginan untuk menyerah, justru semangatnya menjadi berkobar. Sehingga pada akhirnya Raden Wrekudara mampu menaklukan hambatan tersebut.

Dalam arti konotatif, hutan belantara, gunung, jurang dapat diartikan masalah yang datang ketika mencari ilmu. Masalah tersebut dapat dimaknai sebagai hambatan. Hambatan itu harus dilawan, sehingga keberadaanya tidak menggangu jalan pencarian ilmu. Hambatan itu diantaranya rasa malas, jenuh, bosan, tidak taat aturan, dan sebagainya. Untuk itu harus ada nyali dan etos pantang menyerah untuk menaklukkan rasa negatif tersebut. Sehingga tujuan akhir dalam pencarian ilmu dapat dicapai. Periksa kutipan (6).

(6) Dhang Hyang Druna ngrangkul sigra, babo sira lagi sun ayoni, temen nut tuduhing guru, mungko wus kalempahan, nora mengeng ngantepi pituduhingsung, ing mengko sun warah sira, enggone ingkang sayekti. Iya ing theleng samodra, yen sirestu nggeguru marang mami, manjing mring samodra gung. Arya Sena tutira, sampun menggah manjing theleng samudra gung, wantena nginggiling swarga, myang dhasar kasapti bumi. Msa ajriho palastra, 
LINGUA, Vol. 14, No. 2, September 2017

p ISSN: 1979 9411; e ISSN: 2442 238X

Http://lingua.pusatbahasa.or.id; Email: presslingua@gmail.com

Center of Language and Culture Studies, Surakarta, Indonesia

Suprayitno, Edy. 2017. Etika Pengembaraan Masyarakat Jawa pada Naskah Serat Dewa Ruci

Karya R. Ng. Yasadipura I dalam Perspektif Kehidupan Modern.

Lingua (2017), 14(2): 141 154.

anglampahi pituduh paduka yekti, Druna mojr iya kulup, yen iku paduka yekti, bapa kakinira kang wus pada lampus, besuk uripe neng sira, lan sira punjul ing bumi

\section{Terjemahan}

Druna segera memeluk, wahai kau yang sedang kuuji, sungguh mau mengikuti petunjuk gurumu, kini telah terbukti, tidak menolak dalam melaksanakan perintahku, sekarang kuberi petunjuk, tentang letak yang sebenarnya. Yaitu di tengah samudra, jika sungguh kau akan berguru kepadaku, masuklah ke dalam samudra luas itu. Arya sena menjawab, jangankan masuk ke dalam lautan, di puncak surga pun, dan di dasar bumi ketujuh. Tak mungkin takut mati,melaksanakan petunjuk paduka yang benar. Druna berkata ya anakku, jika itu kau temukan, orang tua dan kakekmu yang sudah mati, kelak hidupnya ada padamu, dank au menonjol di dunia ini.

Pendhita Druna kepada muridnya Raden Wrekudara untuk mencari air suci di dasar samudra. Tugas yang diberikan sebenarnya tugas yang tidak masuk akal. Tidak mungkin ada air suci di dasar samudera, selain itu juga tida ada orang yang dapat mencapai dasarnya yang dalam dan luas. Tetapi dengan keteguhan hati dan rasa optimism yang tinggi, Raden Wrekudara menyanggupi tugas tersebut. Dalam kutipan tersebut ditulis //jangankan masuk ke dalam lautan, di puncak surga pun, dan di dasar bumi ketujuh. Tak mungkin takut mati,melaksanakan petunjuk paduka yang benar// hal ini menunjukkan karakter pantang menyerah yang dimiliki oleh Raden Wrekudara dalam mencari air suci.

Kutipan (7) dan (8) menunjukkan karakter pantang menyerah dan pengorbanan yang ditunjukkan Raden Wrekudara sejalan dengan semangat mencari ilmu yang diajarkan dalam budaya Jawa. Dalam tradisi Jawa, sering ditemui manusia Jawa ketika berguru harus dilalui dengan jerih payah. Seperti harus nyantrik dengan memenuhi keinginan guru, mematuhi perintahnya, dan lain-lain. Hakikatnya dalam tradisi Jawa mencari ilmu butuh etos yang kuat. Sehingga etos yang kuat tadi menjadikan manusia Jawa sosok-sosok yang pantang menyerah.

(7) Wrekudara wus prapta, ngadeg neng tepining tasik, mangu-mangu mulat tepining udaya. Kang ombak ngembang gelagah, padukig marang mangsuli, lir nambrama ingkang prapta, ngaturi ngangsulireki, gara reh anekeni, swrane gora gumuntur, alun nulak walikan, palimarma mring kang Prapti, yen ingapu lampahe manjing samudra.

\section{Terjemahan}

Wrekudara sudah sampai, berdiri di tepi laut, ragu-ragu menatap tepi laut. Sang ombak bagaikan bunga gelagah, menggempur batu karang, bagaikan menyambut 
LINGUA, Vol. 14, No. 2, September 2017

p ISSN: 1979 9411; e ISSN: 2442 238X

Http://lingua.pusatbahasa.or.id; Email: presslingua@gmail.com

Center of Language and Culture Studies, Surakarta, Indonesia

Suprayitno, Edy. 2017. Etika Pengembaraan Masyarakat Jawa pada Naskah Serat Dewa Ruci

Karya R. Ng. Yasadipura I dalam Perspektif Kehidupan Modern.

Lingua (2017), 14(2): 141 154.

yang baru datang, menyarankan untuk kembali saja, topan datang juga, suaranya riuh menggelegar, ombak bergulung-gulung, tampak kasihan kepada yang baru datang, bahwa ia ditipu agar masuk ke dalam samudra.

(8) Sarirane Sena kagubet sadaya, mung janggane kang maksih, kang manga sru molah, ningseti panggubetnya, woten palwa dagangprapti, giris umiyat, kang palwa nimpang lebih. Lur sinapon palwa narka angin salah, wau ta kang ginodhi, sayah Arya Bima, kroda emut anulya, cinubles kanaka aglis, kang munggeng angga, pasha ludira mijil. Kuku pancanaka manjing badan naga, tatas sarpa ngemasi, tatas sarpa ngemasi, rah mijil marawan, abang toying samodra, sapan deleng kanan kering, toya awor rah, naga geng wus ngemasi.

\section{Terjemahan}

Sesudah badannya dililit oleh tubuh naga itu, Sena merasa kecut hatinya, melekat ditubuhnya, kebingungan ia mengira akan cepat mati, semakin meronta, sang naga semakin kuat lilitannya. Tubuh Sena dililit semua, hanya tinggal lehernya masih tampak, sang naga semakin ganas, mengencangkan lilitannya, ada kapal dagang yang mendekat, lekas pergi menjauh menghindar. Bagaikan disapu awak perahu itu mengira ada angin salah tiup. Sedangkan saja Sena masih dililit naga, lelh tak kuasa meronta, kemudian dia teringat, segera menikamkan kukunya, tepat ditubuh naga itu, kemudian darahpun memancar. Kuku pancanaka, menancap di badan naga, langsung naga itu mati, darah keluar dengan deras, air laut memerah, tampak sekilas di kanan kiri, air bercampur darah, naga besar sudah mati.

Halangan berupa ombak yang dahsyat dan naga raksasa yang menerkam tidak menjadikan Raden Wrekudara menyerah. Halangan yang datang tersebut dihadapi dengan segenap kemampuannya. Dalam konteks kehidupan nyata, halangan yang kecil sampai yang terbesarpun akan datang menghampiri. Manusia Jawa diajarkan untuk tetap teguh dalam pendirian dan tidak goyah menghadapi masalah tersebut. Sehingga, ketika masalah tersebut berhasil diselesaikan maka akan datang kebahagiaan. Dalam naskah tersebut juga diceritakan setelah naga raksasa dapat dikalahkan, maka Raden Wrekudara bertemu Dewa Ruci yang kemudian mengajarkan ilmu yang dicarinya.

\section{Tidak Mudah Goyah}

Hambatan dalam mencari ilmu pasti ada dan kompleks. Baik hambatan yang berasal dari luar maupun hambatan dalam diri. Maka, butuh kepribadian yang kuat agar tidak mudah goyah menghadapi hambatan-hambatan tersebut. Apabila sekali pendiriannya goyah, maka ilmu yang diinginkan tidak akan didapatkan. Sehingga, tidak mudah goyah merupakan salah satu kunci keberhasilan.

Raden Wrekudara dalam naskah Serat Dewa Ruci karangan R. Ng. Yasadipura I menunjukkan kepribadian yang kuat dalam pengembaraan ilmu. Hambatan 
LINGUA, Vol. 14, No. 2, September 2017

p ISSN: 1979 9411; e ISSN: 2442 238X

Http://lingua.pusatbahasa.or.id; Email: presslingua@gmail.com

Center of Language and Culture Studies, Surakarta, Indonesia

Suprayitno, Edy. 2017. Etika Pengembaraan Masyarakat Jawa pada Naskah Serat Dewa Ruci

Karya R. Ng. Yasadipura I dalam Perspektif Kehidupan Modern.

Lingua (2017), 14(2): 141 154.

dari luar dan dalam dirinya mampu ditaklukannya, sehingga mengantarkan Raden Wrekudara mendapatkan ilmu sangkan paraning dumadi. Periksa kutipan (9).

Praptamu nedya sikara, nora wurung karasa ngasto mami, ditya kekalih gya naut, Rukmuka Rukmukala, pan sarya nggro Dyan Wrekudara tinubruk, kinerah gulu iringnya, ginilut ing kanan kiring. Panggeh Raden Wrekudara, jangganira kinerah datan gingsir, kinemah ginilut-gilut, jangganira tan pasah....

\section{Terjemahan}

Kedatanganmu akan mengganggu, tak pelak tentu akan menerima tamparanku, kedua raksasa menyahut, Rukmuka dan Rukmukala, sambil menggeram mereka menerkam Wrekudara, menggigit leher samping, dikeroyok kanan kiri. Wrekudara tetap tangguh, lehernya digigit tidak apa-apa, dikunyah digulat tidak mempan....

Dalam pencarian air suci Perwitasari di Goa Tribasara, Raden Wrekudara bertemu dengan 2 raksasa yang merasa terganggu dengan kedatangannya. Kemudian raksasa itu mengeroyok dan berusaha membunuh Raden Wrekudara. Tapi kebengisan dan keangkeran raksas itu tidak meruntuhkan keteguhan hati Raden Wrekudara. Dalam konteks kehidupan nyata kedua raksasa itu dapat diibaratkan hambatan pengembaraan ilmu. Hambatan tersebut dapat berupa permasalahan pribadi, gesekan dengan orang lain, rasa malas, dan lain-lain. Sehinggah, terkadang berbagai permasalahan tersebut apabila tidak disikapi dengan bijak akan menggoyahkan seseorang dalam pencarian ilmu. Di sini Raden Wrekudara memberikan contoh bahwa hambatan dalam pencarian ilmu harus dihadapi dan dikalahkan, sehingga apa yang menjadi tujuan akhir dapat tercapai. Periksa kutipan (10).

(10) Sena tan kena ingampah, tan keguh ginubel tangis. Dananjaya nyepeng asta, ari kalih suku kalih, pan sarwa lara tangis, Sri Kresna tansah pitutur, Srikandhi lan Subadra, kang samya nggubel nangisi, kinpatken sadaya sami kaplesat. Mekso mberot Wrekudara datan keno den gujengi, ngithar jampahe wus tebah, kadya tinilar ngemasi.

\section{Terjemahan}

Wrekudara tidak dapat ditahan lagi, tak goyah dikungkung oleh tangis. Dananjaya memegangi tangan, dua adik lain memegangi kedua kakinya, dan sambil menangis mengiba-iba. Sri Kresna selalu menasehati, Srikandi dan Subadra yang masih tetaap menangis dan menghalang-halangi, dikibaskan semua terlempar. Wrekudara tak dapat dipegangi, cepat langkahnya sudah jauh, yang ditinggal bersedih bagaikan ditinggal mati. 
LINGUA, Vol. 14, No. 2, September 2017

p ISSN: 1979 9411; e ISSN: 2442 238X

Http://lingua.pusatbahasa.or.id; Email: presslingua@gmail.com

Center of Language and Culture Studies, Surakarta, Indonesia

Suprayitno, Edy. 2017. Etika Pengembaraan Masyarakat Jawa pada Naskah Serat Dewa Ruci

Karya R. Ng. Yasadipura I dalam Perspektif Kehidupan Modern.

Lingua (2017), 14(2): 141 154.

Dalam pencarian ilmu, terkadang orang terdekat dapat menjadi penghambat. Seperti orang tua yang keberatan apabila anaknya akan melanjutkan ke perguruan tinggi karena ketiadaan biaya. Hambatan ini harus disikapi dengan arif. Seorang anak harus mampu menjelaskan tentang niat dan usaha yang ingin dilakukannya. Sehingga, tidak ada kesalahpahaman antara anak dengan orang tua. Kutipan di atas, pada hakikatnya merupakan salah satu wujud hambatan yang datang dari orang terdekat. Dalam hal ini para saudara Pandawa tidak mengizinkan Raden Wrekudara menuruti perintah Pendhita Druna. Tapi keteguhan hati Raden Wrekudara tidak dapat digoyahkan lagi.

\section{Patuh Perintah Guru}

Menghormati guru merupakan sebuah keharusan bagi seseorang yang sedang berguru. Guru ibarat orang tua yang senantiasa mengajarkan agar menjadi bisa. Maka keberadaannya wajib dihormati selayaknya mengormati orang tua. Bentuk penghormatan kepada guru bisa berupa tutur kata yang sopan, mendengarkan nasehatnasehatnya, dan mematuhi semua perintahnya. Keberadaan seorang guru merupakan sosok penting dalam pencarian ilmu. Kutipan (11) menunjukkan ilmu sulit didapatkan apabila tidak ada guru yang senantiasa membimbing dan mengarahkan.

(11) Wrekudara miyarsa, sengkut pamrihipun, sang saya birahinira, iya marang kawusaning ngaurip, sampurnaning panunggal. Sirna parang prakara na malih, urub siji wolu warnanira. Wrekudara lo nature, punapa wastanipun, urub siji wolu kang warni.....

\section{Terjemahan}

Wrekudara mendengar, dengan giat ia berusaha dengan penuh tekad, untuk mencapai pedoman hidup, demi kesempurnaan persatuan. Setelah hilang empat, hal itu ada lagi, nyala satu delapan warnanya. Wrekudara pelan bertanya, apakah namanya, nyala satu dengan warna......

Mendengarkan petuah guru dengan sikap sopan merupakan salah satu bukti kepatuhan guru terhadap murid. Hal ini tercermin dalam kutipan tersebut. Raden Wrekudara dengan penuh kesungguhan hati mendengarkan nasehat dan piwulang dari Dewa Ruci. Mendengarkan dengan sungguh-sungguh bertujuan agar semua perkataan yang keluar dari sang guru dapat didengar dengan baik. Kemudian nasihat tersebut dapat dipahami dan dimaknai.

Pola belajar yang dilakukan oleh Raden Wrekudara tersebut tentunya juga sudah diajarkan leluhur Jawa sejak zaman dahulu. Masyarakat Jawa dahulu ketika diajar guru maka murid dilarang untuk bersuara. Apabila bersuara akan mendapatkan hukuman. Tujuannya (a) membentuk karakter yang menghargai, (b) agar penjelasan mudah didengar dan dipahami, dan (c) sebagai bukti ketaqdiman seorang murid kedapa guru. Pola pengajaran behavioristik itu pada akhirnya membentuk manusia Jawa yang sangat menghormati guru. 
LINGUA, Vol. 14, No. 2, September 2017

p ISSN: 1979 9411; e ISSN: 2442 238X

Http://lingua.pusatbahasa.or.id; Email: presslingua@gmail.com

Center of Language and Culture Studies, Surakarta, Indonesia

Suprayitno, Edy. 2017. Etika Pengembaraan Masyarakat Jawa pada Naskah Serat Dewa Ruci Karya R. Ng. Yasadipura I dalam Perspektif Kehidupan Modern.

Lingua (2017), 14(2): 141 154.

Pola pembelajaran tersebut terlihat berbeda dengan pola pembelajaran modern. Pembelajaran modern lebih menekankan siswa yang aktif untuk menggali pengetahuan mereka sendiri. Sedangkan guru hanya sebagai fasilitator, administrator, motivator, dan manajer kelas. Tetapi yang menjadi masalah, apabila guru tidak punya keahlian pedagogik yang mumpuni, maka kondisi kelas sulit dikendalikan. Sehingga, pola pembelajaran modern tidak hanya membutuhkan sosok guru yang dapat mengajar, tetapi juga sosok guru yang kompleks. Seperti sosok guru sebagai manajer kelas, motivator, fasilitator, dan admisnistrator. Periksa kutipan (12).

(12) Dhang Hyang Druna ngrangkul sigra, babo sira lagi sun ayoni, temen nur tuduhung guru, mungko wus kalampahan nora mengeng ngantepi pituduhingsun, ing mengko sun warah sira, enggone ingkang sayekti. Iya ing theleng samodra, yen sirestu nggeguru marang mami, manjinga mring samodra gung.

\section{Terjemahan}

Druna segera memeluk, wahai kau yang sedang kuuji, sungguh mau mengikuti petunjuk gurumu, kini telah terbukti, tidak menolak dalam melaksanakan perintahku, sekarang kuberi petunjuk, tentang letak yang sebenarnya. Yaitu di tengah samudra, jika sungguh kau akan berguru kepadaku, masuklah ke dalam samudra luas itu.

Mematuhi perintah guru merupakan sebuah kewajiban bagi seorang murid. Karena di balik perinta guru pasti ada tujuan dan manfaat yang dapat diperoleh seorang murid. Kutipan di atas menyiratkan sikap patuh yang tinggi pada diri Raden Wrekudara. Hal ini tercermin dalam kesediaannya menunaikan tugas untuk mencari air suci di dasar samudera. Tugas yang mustahil untuk dapat diselesaikan. Tapi rasa taqdim Raden Wrekudara mampu mengalahkan kemustahilan tadi.

Nilai kepatuhan yang dicontohkan Raden Wrekudara harusnya dapat direfleksikan dalam kehidupan nyata. Sebab era modern ini nilai kepatuhan kepada guru mulai luntur. Adanya kasus siswa di Sidoarjo yang melaporkan gurunya karena merasa dianiaya, kemudian ada siswa dan orang tua siswa yang ramai-ramai memukuli gurunya, merupakan bukti mulai lunturnya nilai-nilai kepatuhan terhadap guru. Lunturnya sikap kepatuhan terhadap guru perlu adanya pembenahan. Karena apabila dibiarkan ke depan akan berdampak negatif.

\section{SIMPULAN}

Berdasarkan penelitian di atas, dapat disimpulkan naskah Serat Dewa Ruci karangan R.Ng. Yasadipura I memiliki nilai etika dalam menuntut ilmu. Nilai tersebut merupakan ajaran dalam budaya Jawa yang turun-temurun diajarkan. Ajarann tersebut tercermin dalam berbagai karya sastra Jawa. Nilai dalam naskah Serat Dewa Ruci karangan R.Ng. Yasadipura I perihal menuntut ilmu tersebut antara lain, (a) semangat, 
(b) pantang menyerah, (c) tidak mudah goyah, dan (d) patuh terhadap guru. Nilai dalam menuntut ilmu seperti yang dilakukan oleh Raden Wrekudara di era modern cenderung mengalami penurunan. Beberapa bukti perilaku pelajar yang menyimpang seperti, (a) tindak kriminalitas, (b) tawuran, (c) penyalahgunaan narkoba, (d) berani kepada guru, dan sebagainya. Bukti itu merupakan adanya penurunan etika menuntut ilmu di era modern.

\section{DAFTAR PUSTAKA}

Endraswara, Suwardi. 2010. Falsafah Hidup Jawa. Yogyakarta: Cakrawala Belajar 2011. Metodologi Penelitian Sastra. Yogyakarta. CAPS.

Damono, Sapardi Djoko. 1984. Sosiologi Sastra Sebuah Pengantar Ringkas. Jakarta pusat: Pembinaan dan Pengembangan Bahasa Dekdipbud.

Moleong, Lexy J. 2007. Metodologi Penelitian Kualitatif. Bandung: Penerbit PT Remaja Rosdakarya Offset.

Santoso, Iman Budi. 2010. Nasihat Hidup Orang Jawa. Jogjakarta: Diva Press

Wibawa, Sutrisna. 2013. Diktat Mata Kuliah Etika Jawa. Yogyakarta: UNY 
LINGUA, Vol. 14, No. 2, September 2017

p ISSN: 1979 9411; e ISSN: 2442 238X

Http://lingua.pusatbahasa.or.id; Email:presslingua@gmail.com

Center of Language and Culture Studies, Surakarta, Indonesia

Suprayitno, Edy. 2017. Etika Pengembaraan Masyarakat Jawa pada Naskah Serat Dewa Ruci Karya R. Ng. Yasadipura I dalam Perspektif Kehidupan Modern.

Lingua (2017), 14(2): 141 154. 